\title{
La entrevista de los lectores: en la convergencia de medios y audiencias activas. Posibilidades y retos para la participación del lector
}

\author{
Antonio López HidALGO \\ lopezhidalgo@us.es \\ Universidad de Sevilla \\ Ángeles FERNÁNDEZ BARRERO \\ mfernandez10@us.es \\ Universidad de Sevilla
}

Recibido 15 de enero de 2014

Aceptado: 8 de julio de 2014

\begin{abstract}
Resumen
Los cibermedios han desarrollado fórmulas orientadas a la participación de las audiencias, como los géneros dialógicos, que favorecen la colaboración entre medios y audiencias. El presente trabajo ofrece un estudio conceptual de las entrevistas de los lectores y analiza estos productos desde una perspectiva práctica. Además, reflexiona sobre el papel que debe asumir el periodista como moderador. A partir de la revisión bibliográfica, el análisis comparado de textos y entrevistas no estructuradas, el trabajo aborda la dinámica de composición de estos géneros. Los resultados demuestran que estas entrevistas favorecen la proximidad del medio y la integración horizontal de contenidos aficionados y profesionales en un solo género pero también revela que la participación del lector en la producción informativa es limitada y aún se debe afrontar el desafío de la visibilidad.
\end{abstract}

Palabras clave: Cibermedios, géneros periodísticos, periodismo participativo, entrevistas, comunicación interactiva.

\section{Online collective interviews: converging media and active audiences. Possibilities and challenges for readers' participation}

\begin{abstract}
Cybermedia have developed narrative formulas focused on participation of the audience, such as dialogic genres, which prioritize media and active audience's collaboration options. This article presents a conceptual study about online interviews possibilities and analyzes these products from a practical perspective. It also intends to discuss about the new functions that journalists assume as moderators. The paper is based on literature review, comparative analysis of texts and unstructured interviews in order to study the composition of these texts. The research findings show that online interviews favor the proximity media and the horizontal integration of amateur and professional content. Also it reveals that readers' participation is limited while visibility must be improved.

Keywords: Cybermedia, journalistic genres, participative journalism, interviews, interactive communication.

Referencia normalizada

LÓPEZ HIDALGO, Antonio y FERNÁNDEZ BARRERO, Ma Ángeles (2015): “La entrevista de los lectores: en la convergencia de medios y audiencias activas. Posibilidades y retos para la participación del lector". Estudios sobre el Mensaje Periodístico. Vol. 21, Núm. 1 (enero-junio), págs.: 353-367. Madrid, Servicio de Publicaciones de la Universidad Complutense.
\end{abstract}

Sumario: 1. Introducción; 1.1. Antecedentes; 1.2. Géneros para la participación en los medios en línea; 1.3. Las entrevistas de los lectores. 2. Metodología. 3. Resultados: dinámica de las entrevistas de los lectores en elpais.com y el elmundo.es. 4. Conclusiones. 5. Referencias bibliográficas. 


\section{Introducción}

Como en su día sucedió con los medios audiovisuales, los géneros tradicionales se han adaptado a los medios en línea con algunos cambios, aunque también han aprovechado las características propias de su naturaleza, eminentemente digital, para fomentar fórmulas narrativas propias, que aprovechan al máximo las posibilidades de hipertextualidad e interactividad de los medios en red, especialmente las dirigidas a la participación de los lectores.

Pese a ello, aún hay un importante número de diarios que se limitan a recoger las informaciones de la edición impresa sin apenas modificaciones y los que reproducen las mismas estructuras discursivas explotadas ya por los medios de comunicación tradicionales, siguiendo un "modelo facsimilar" y/o "adaptado", según la terminología utilizada por Cabrera González (2001: 75), modelos estáticos y de poca utilidad para el lector, pues no se aprovechan las posibilidades de interactividad que ofrece el nuevo medio. El futuro de los medios en línea pasa por "una verdadera renovación de los formatos preexistentes" (Mancera, 2011: 90), aprovechando al máximo las cualidades del lenguaje hipertextual, la interacción y los recursos multimedia que caracterizan la comunicación digital. En este contexto, y al amparo de medios que apuestan por la innovación, se están desarrollando nuevos géneros periodísticos nacidos para la Red, aunque en muchos casos son productos experimentales que se desarrollan en un entorno dinámico y en constante evolución. Pese a su parecido con las estructuras prototípicas de los géneros tradicionales, estos géneros constituyen una apuesta decidida por desarrollar fórmulas narrativas adaptadas a la naturaleza del ciberespacio.

Sobre su clasificación, los autores que se han adentrado en su estudio insisten en la heterogeneidad de fórmulas, aunque coinciden en subrayar su orientación a la participación activa de las audiencias. En cualquier caso, la participación del público en los contenidos no es una innovación de los medios en línea. De hecho, las cartas al director gozan ya de bastante tradición en los medios impresos. Internet, no obstante, ha supuesto toda una revolución en cuanto a las fórmulas de interacción con los lectores. En opinión de Concha Edo (2009: 10), de las cuatro características básicas que definen el marco comunicativo de Internet, a saber, la hipertextualidad, la multimedialidad, la interactividad y la actualización continua, una de las propiedades que verdaderamente está marcando el cambio de trabajo en las redacciones y la respuesta de la audiencia, es la interacción informativa con los lectores.

El grupo de cibergéneros orientados a la participación del lector, y el caso particular de las entrevistas de los lectores, representa una apuesta decidida para favorecer la emisión de contenidos íntegramente digitales que priorizan el protagonismo interactivo de los lectores, en los que el periodista, como consecuencia, asume nuevas funciones como moderador. La bibliografía sobre estos cibergéneros es aun escasa debido, en gran medida, a la relativa juventud de estos productos, y la mayoría de los estudios presentan un enfoque eminentemente teórico, por lo que se hace necesario indagar acerca de la dinámica que siguen los medios y cómo se articulan en la práctica periodística diaria estos nuevos códigos de la comunicación, así como reflexionar acerca de las aportaciones que representan en el panorama actual de los géneros ciberperiodísticos y la colaboración que pueden desarrollar en este contexto periodistas y audiencias activas. 


\subsection{Antecedentes}

Para adentrarnos en el estudio de la participación de los lectores en los medios tendríamos que remontarnos a las cartas de los lectores, cuyo origen se retrotrae a principios del siglo XVIII, en Inglaterra, como aportación de Dunton y Daniel Defoe. Las cartas de los lectores introducen una nueva forma de retroalimentación en un proceso de comunicación que hasta entonces mantenía un sentido unidireccional. Este género representa, por tanto, un grado básico y de participación de los lectores, pues existe una selección previa de estos trabajos, independientemente de los fines a los que responda, y en la mayor parte de los casos carecen de respuesta. El entorno digital ha subsanado las carencias de este género ya tradicional en la prensa escrita, ampliando su horizonte.

La prensa convencional también ahondó en otras fórmulas para la participación de los lectores, recabando, por ejemplo, su opinión en encuestas, o incluso solicitando su colaboración a través del envío de imágenes emotivas de la ciudad, especialmente en los medios más locales, o de denuncia. Las posibilidades para la participación son, en todo caso, limitadas, en el caso de la prensa escrita, pues apenas existen posibilidades para una retroalimentación continua entre el medio y sus lectores.

Pero antes de que todos los hogares del mundo abrieran sus puertas a Internet, los medios audiovisuales habían buscado ya múltiples fórmulas de participación dialógica de la audiencia, explotando así la naturaleza audiovisual del medio más allá de los géneros convencionales de la prensa escrita. La participación de los oyentes en los contenidos y emisiones en los medios audiovisuales ha sido reivindicada por autores clásicos como Brecht y Enzensberger como una salida necesaria para un verdadero uso comunicativo del medio, en aras de una comunicación emancipadora. Desde el punto de vista de los géneros, se traduce en la proliferación de formatos y géneros para la participación de los oyentes y espectadores.

En lo que se refiere a la radio, Susana Herrera Damas asegura que, al menos desde los años cuarenta, la participación ha estado orientada a "una finalidad lúdica y divulgativa, caracterizada por ser numéricamente reducida y técnicamente limitada y típica" (Herrera Damas, 2003: 146), que se manifiesta, por ejemplo, en emisiones como los concursos, los consultorios, la denominada "radio de beneficencia" o los programas de discos dedicados. Esta autora observa, no obstante, que en las últimas décadas, las innovaciones narrativas y tecnológicas que han afectado al discurso radiofónico han desembocado en una evolución paralela de las intervenciones de los oyentes, que puede consistir en expresar una opinión, rectificar una información, aportar información, relatar un caso propio o ajeno, consultar una información, denunciar un hecho o situación o desahogarse, entre otras funciones (Herrera Damas, 2003: 158). En función de los códigos lingüísticos utilizados, clasifica la participación de los oyentes en códigos lingüísticos escritos, a través de las cartas o de Internet, y códigos orales, una modalidad en la que incluye las distintas posibilidades participativas en las que "se inserta la voz del oyente, ya sea a través del teléfono, del contestador automático o del buzón de voz, de manera presencial, o mediante la técnica del chat de voz o del vox pop" (Herrera Damas, 2003: 158). También incluye en este apartado las intervenciones seleccionadas por el portavoz del oyente y a las que se da paso en antena. 
La realización técnica desemboca, según esta autora, en intervenciones que se realizan en directo, bien de manera presencial o por teléfono, o en diferido, a través de cartas, fax, mensajes depositados en un buzón de voz, correo electrónico, lectura de chats o la técnica del vox pop, que supone "que el redactor de un espacio determinado sale previamente a la calle para, grabadora en mano, sondear el estado de una parte de la opinión pública mediante la formulación de una pregunta" (Herrara Damas, 2003: 163).

Por su parte, Cebrián Herreros (195: 40), desde una perspectiva más centrada en los géneros audiovisuales, insiste en que estos medios han ido desarrollando géneros adaptados a su naturaleza audiovisual, que cataloga como "apelativos o dialógicos", por estar basados en el diálogo. Al margen de la entrevista, la encuesta, la rueda de corresponsales, la conferencia de prensa, la rueda informativa en estudio y los géneros coloquiales y de debate, identifica en este gran bloque de géneros dialógicos un subgrupo de géneros para la participación dialógica de la audiencia, entre los que destaca los consultorios radiofónicos y los interrogatorios de la audiencia. Tanto la radio como la televisión permiten, además, la participación telefónica del espectador o del oyente con preguntas en entrevistas o tertulias, el envío de vídeos denunciando cualquier situación o bien la filmación fortuita de una catástrofe natural. Todas estas posibilidades se han visto amplificadas con el desarrollo de los medios en línea, en la medida que permiten aprovechar al máximo el lenguaje multimedia y la interactividad. Pese a que los formatos pueden variar, en la mayoría de los casos la participación del internauta está sujeta a la moderación de periodistas profesionales, que puede ejercerse en distintos grados (Hermida and Thurman, 2008: 346).

\subsection{Géneros para la participación en los medios en línea}

La interactividad proporcionada por los medios digitales ha potenciado el papel del público hasta límites nunca antes sospechados. Esta cualidad, no obstante, puede ser utilizada en distintos grados, en función del nivel de retroalimentación que se establezca o la libertad de la que disponga el internauta para intervenir en los contenidos.

En un primer grado, las informaciones de los diarios en red permiten al lector el envío automático de correos electrónicos al redactor de la información, así como la inserción de comentarios, que deben ser aceptados previamente por el medio antes de su publicación, de manera que se establece un filtro que vela por la idoneidad de los mensajes. Las cartas de los lectores permiten visualizar la opinión de los lectores respecto a temas de interés informativo. Además, las encuestas ofrecen a los lectores la posibilidad de posicionarse respecto a determinados temas propuestos por el medio, sobre los que deben pronunciarse a través de un sistema de votación, seleccionando una respuesta cerrada, generalmente sí o no, o incluso varias respuestas cerradas. Se trata, por tanto, de una participación limitada y circunscrita a unos estrictos márgenes establecidos por el medio.

En un segundo grado de interactividad, los foros, los canales de charla (chats) o las entrevistas en línea representan modelos más evolucionados de participación de la audiencia, dado que ofrecen un valor añadido al comentario de las informaciones, pues permiten la interacción y ofrecen al usuario una mayor libertad en su participación. Se 
trata de los géneros dialógicos para la participación en los medios en línea. En este sentido, Javier Díaz Noci (2004) ha apuntado que este tipo de cibergéneros entran dentro del concepto de dialogismo. Por su parte, Ramón Salaverría los define así: "Aquellos que se basan en la comunicación entre dos o más personas a través de textos escritos u orales, y que pueden realizarse de forma sincrónica (los protagonistas establecen una comunicación en un tiempo simultáneo) o asincrónica (el intercambio de mensajes no es instantáneo, sino diferido)" (Salaverría, 2005: 169).

El foro es el género en el que bajo la moderación de un especialista, el usuario puede participar en temas abiertos o monográficos en torno a una actualidad más o menos efímera o permanente e incluso puede proponer temas para su debate. El chat es una aplicación que permite la comunicación simultánea o sincrónica entre usuarios sobre cuestiones relacionadas con la actualidad, pero también con el entretenimiento. La entrevista de los lectores mantiene un mayor arraigo con los géneros tradicionales de la prensa escrita, aunque en la modalidad en la que nos detenemos el periodista cede su papel a los lectores, participando, así, en el proceso de creación de la información.

Un tercer grado de interactividad estaría constituido por la participación del internauta en los contenidos informativos. Según Javier Díaz Noci (2004), la investigadora inglesa de la Universidad de Sussex Anne Light ya distingue entre dos tipos de interactividad en los medios: la inclusiva, en la que la audiencia colabora en la obtención del producto informativo, y el modelo autorial, en el que se permite participar a los usuarios, pero no hasta el punto de intervenir en la confección del ítem noticioso. Internet ofrece a los ciudadanos la posibilidad de participar con el envío de fotos o vídeos. Se trata de una fórmula que se remonta a 1963, cuando un aficionado grabó casualmente en vídeo el magnicidio del presidente Kennedy en Dallas. Hoy es una práctica muy extendida, aunque cada vez más los medios procuran reservar al periodista una función de filtro.

Finalmente, un cuarto nivel de interactividad estaría constituido por la máxima expresión de este modelo, que ha desembocado en los ya conocidos diarios ciudadanos, creados por expertos usuarios en tecnología capaces de configurar diarios personales a medida de los intereses particulares, con apenas intermediación de periodistas profesionales. En este contexto se ha reavivado la idea de que los periodistas tradicionales han perdido el monopolio sobre la función informativa, circunstancia que obliga a replantear el papel del periodismo profesional en una sociedad en continuo cambio. Según Negredo (2013: 17), el periodismo participativo atraviesa una etapa en la que la colaboración de periodistas y medios de comunicación y audiencias está siendo reconsiderada y reajustada.

\subsection{Las entrevistas de los lectores}

Del grupo de cibergéneros orientados a la participación del lector sólo tres productos se caracterizan por su carácter dialógico: las entrevistas de los lectores, los foros y los chats, en la medida que incorporan la bidireccionalidad propia del diálogo. Además, ofrecen un grado de interactividad secundario o funcional (Deuze, 2003: 214). En este contexto, los autores insisten en el nuevo papel que debe afrontar el periodista profe- 
sional, asumiendo nuevas funciones, como la generación de debates o la coordinación y el filtrado de textos.

Las entrevistas de los lectores están adquiriendo tanta importancia en los medios en línea que algunos autores, como Ana Mancera, aseguran que en los cibermedios podemos encontrar básicamente dos tipos de entrevistas: "Aquellas en las que un periodista interroga a un personaje, y redacta a continuación un texto, en el que reproduce -y edita en mayor o menor medida- sus palabras; y las 'charlas' o 'encuentros digitales' de los lectores con uno de los protagonistas de la actualidad noticiosa" (Mancera, 2011: 245).

El primer grupo sigue teniendo una importante presencia en los medios digitales. La entrevista es, de hecho, uno de los géneros más clásicos de la Redacción Periodística. Son varios los autores que reconocen como pionera la entrevista realizada en 1836 por James Gordon Bennet, director del New York Herald, a la propietaria de una casa donde se había encontrado a una mujer muerta a golpes de hacha, aunque para otros autores la primera entrevista completa a un personaje conocido la obtuvo Horace Greeley en 1859, para el Tribune de Nueva York, en un encuentro que mantuvo con el fundador de los mormones, Brigham Young (López Hidalgo, 1999: 68). En tan sólo una década, este género, que fue aceptado con gran popularidad entre los lectores, se generalizó entre los medios escritos. Los medios audiovisuales y los medios en red han importado este género y lo han adaptado con nuevas fórmulas a su naturaleza audiovisual y digital.

Por otro lado, las entrevistas de los lectores se han consolidado en los medios en línea como instrumento que favorece la proximidad del medio y la máxima integración horizontal de los contenidos aficionados y profesionales en un solo género, de ahí que Salaverría lo califique como "uno de los formatos más novedosos y exitosos en los cibermedios" (Salaverría, 2005: 171). También conocida en la bibliografía y la praxis profesional como entrevista en línea, entrevista digital, entrevista participativa, entrevista interactiva, encuentro digital o charla con los usuarios, permite a los internautas entrevistar, de manera conjunta, a un personaje de actualidad propuesto por el medio. En ocasiones, señala Díaz Noci (2001: 125) estas entrevistas en línea se utilizan total o parcialmente en la edición impresa del diario, con lo cual la retroalimentación se da también al revés.

El cuanto a la dinámica de composición, el medio cita a los internautas un día y a una hora concreta, y anuncia la presencia del personaje de actualidad, que podrá ser entrevistado con suficiente tiempo de antelación. Durante un espacio de tiempo determinado, normalmente una hora, este personaje responderá a las preguntas de los usuarios (proceso simultáneo), aunque también existe la posibilidad, menos frecuente, de establecer un sistema asíncrono, en el que, como advierte Salaverría (2005: 171), las preguntas se han enviado los días anteriores al medio, de manera que el periodista las remite al entrevistado; una vez contestadas, se publica todo el texto. Esta segunda modalidad es menos frecuente, pues el directo confiere un plus de credibilidad al género que afianza a los lectores, aunque, en cualquier caso, la modalidad asincrónica garantiza un número seguro de preguntas. En ocasiones, además, en la variante en directo los usuarios pueden ver al entrevistado a través de una webcam mientras éste teclea las respuestas a las cuestiones planteadas. 
El entrevistado lee en la pantalla las preguntas que le van planteando los usuarios y contesta escribiéndolas en el ordenador. A este respecto, Bill Keller, director de The New York Times, reconoce en una entrevista publicada en elpais.com (2010) que los lectores hacen muy buenas preguntas. La figura del entrevistado también es clave. Suele ser un personaje público, de actualidad, cuyas declaraciones pueden pasar a ser noticia. A este respecto, Salaverría (2005: 171) y Ana Mancera (2011: 245) también identifican un grupo peculiar de entrevistas de los lectores en las que el entrevistado en un periodista especializado, que mantiene una cita aproximadamente semanal con los lectores, siempre en día y hora fijos, como si de un programa de radio se tratara. Esta última modalidad de entrevista, no obstante, está emparentada igualmente con un género ya clásico en los medios audiovisuales, el consultorio radiofónico, en el que predomina una finalidad formativa e instructiva, a diferencia de lo que sucede con la entrevista, en la que prima el fin informativo.

Al mismo tiempo, en las entrevistas de los lectores un periodista modera, filtra y selecciona las cuestiones que se someten a las consideraciones del personaje invitado. La singularidad de esta modalidad de entrevista es que el papel de intermediario del periodista es muy sutil y puede pasar ante los ojos del lector casi desapercibido. De esta forma, como advierte Salaverrría, la importancia del autor se pierde, en parte, para que cobre mayor protagonismo el lector. "El público recupera un protagonismo perdido en los medios tradicionales frente al autor omnipresente, el periodista, que ahora debe afrontar un papel de 'moderador' más que de gatekeeper" (Salaverría, 2005: 170). Mancera, por su parte, sostiene que en este género el moderador se convierte en un mero moderador de la charla, función que define como sycop, acrónimo de system operator, cuya función "se limita a la de seleccionar las preguntas -para que, por ejemplo, el entrevistado no se vea obligado a responder a comentarios ofensivos- y ordenarlos con el fin de que el encuentro digital esté dotado de una cierta coherencia" (Mancera, 2011: 247). La selección se realiza atendiendo a criterios básicamente periodísticos. Según Veglis y Pomportis (2012: 10), las entrevistas de los lectores conllevan la modalidad específica de "premoderación", es decir, la aportación de los usuarios es revisada antes de su publicación.

Para Mancera, este tipo de intermediación que se establece entre el entrevistado y los lectores también tiene un aspecto negativo, pues "se pierde la intimidad del contexto entre los dos" y, por tanto, se rebaja la capacidad de seducción de un encuentro directo. En resumen, la participación de los lectores provoca que este género asuma un tono coral muy característico. Como señala Javier Mayoral (2013: 233), "se pierde la coherencia temática de la conversación establecida entre solos dos interlocutores, pero el nuevo formato aporta variedad y espontaneidad".

\section{Metodología}

Desde el punto de vista metodológico, ofrecemos un estudio conceptual de los géneros dialógicos para la participación del internauta, y del caso particular de las entrevistas de los lectores, su dinámica de composición y sus elementos compositivos, a partir de la revisión bibliográfica y el análisis descriptivo de textos con carácter comparativo. 
Para el análisis hemos seleccionado dos medios en línea españoles con una amplia trayectoria en la Red, El Mundo y El País Digital, sobre los que se ha efectuado un seguimiento a lo largo de la primera quincena de septiembre de 2013. Se trata de dos medios con un elevado nivel de difusión e influencia en la opinión pública, que gozan ya de una importante tradición en el universo digital, que les confiere solvencia y credibilidad. El Mundo y El Periódico de Cataluña ya publicaban en Servicom en 1994 (Salaverría, 2007: 358). Un año después, en 1995, se produce un salto paulatino de las publicaciones a la nueva red libre y mundial, la World Wide Web, en la que se adentraron, según Salaverría, los catalanes Avui (1 de abril) y La Vanguardia (14 de junio), El Diario Vasco de San Sebastián (en agosto), y $A B C$ (el 20 de septiembre). Algunos autores citan experiencias previas, como la versión electrónica de la revista cultural El Temps de Valencia, en 1994, el Boletín Oficial del Estado, también en 1994, y del Diario Expo 92, que se mantuvo en la Red a lo largo de seis meses de 1992, como ha constatado Álvarez Marcos (2000), y podía ser consultado en unos terminales dispuestos al efecto en el recinto ferial de la Exposición Universal de Sevilla. La versión digital de El País se inaugura en la Web el 4 de mayo de 1996, coincidiendo con su vigésimo aniversario en los quioscos.

Tanto El País Digital como elmundo.es cuentan, además, con una cabecera impresa de referencia. Esta circunstancia condiciona sus contenidos, pues las versiones de ambos medios se retroalimentan constantemente en cuanto a materias y géneros, lo que, en todo caso, no ha impedido que apuesten por la innovación en los formatos.

El análisis descriptivo de textos se ha completado con entrevistas no estructuradas a los responsables de este género en ambos medios, Miguel Medina' ${ }^{1}$, coordinador de participación digital en El País Digital y Custodio Pastor', coordinador de los 'Encuentros' de elmundo.es, que han aclarado distintos aspectos que difícilmente pueden desprenderse del análisis, como, por ejemplo, la dinámica de las entrevistas, el recibimiento de los personajes entrevistados o el papel que el periodista desempeña en el desarrollo de la entrevista.

\section{Resultados: dinámica de las entrevistas de los lectores en elpais.com y el el- mundo.es}

Tanto El País como El Mundo potencian la accesibilidad y visibilidad de la sección de entrevistas de los lectores al colocar en la página de inicio del diario la entrevista del día, cuando la hay, desde la que se enlaza a las demás, de manera que este género para la participación de los lectores, pese a tratarse de una sección diferenciada, denominada "Entrevistas digitales" en El País Digital y "Encuentros" en El Mundo, se integra entre los contenidos del diario con naturalidad.

En las entrevistas de un gran interés informativo elmundo.es refuerza la visibilidad con anuncios publicitarios de los encuentros en la versión impresa del medio. En

1 Entrevista no estructurada mantenida con Miguel Medina, coordinador de Participación Digital de El País, con fecha 16-09-2013.

2 Entrevista no estructurada mantenida con Custodio Pastor, coordinador de los Encuentros de El Mundo, con fecha 16-09-2013. 
ambos medios, al no tener las entrevistas una periodicidad ni un horario fijo cobra una relevancia especial el anuncio de la entrevista. Las próximas entrevistas se pueden anunciar con varios días de antelación, aunque en definitiva depende de la actualidad, del interés informativo, de cuándo se ha cerrado la entrevista o incluso de intereses estratégicos. En este anuncio se ofrece alguna información sobre el entrevistado para que los internautas puedan planificar su intervención.

En cuanto a la dinámica de las entrevistas, ambos medios apuestan por la entrevista sincrónica, como manifiestan los responsables de este género en elpais.com y elmundo.es, Miguel Medina y Custodio Pastor, respectivamente, en la medida que aporta la vivacidad y naturalidad del directo. Además, en el caso de elmundo.es, se realizan desde la propia redacción del periódico, exceptuando casos muy puntuales en los que el medio tiene interés en algún personaje y por algún motivo de importancia no puede estar en Madrid, aunque son, en todo caso, mínimas excepciones. El País Digital opta por ambas variantes y, por tanto, las entrevistas que no están realzadas desde la redacción del diario son más frecuentes que en otros medios. Al entrevistado, en estas ocasiones, se le envía un correo electrónico con un enlace a una página desde la que puede ir contestando a las preguntas.

La elección del entrevistado es un momento crucial de la entrevista, en la que priman fundamentalmente criterios de actualidad. El funcionamiento, no obstante, difiriere notablemente en los medios analizados. En El País depende fundamentalmente de las peticiones de otras secciones informativas, que son las que cierran la entrevista. Cultura, por ejemplo, es una de las secciones que demanda un mayor número de entrevistas. En El Mundo, por el contrario, los Encuentros disponen de un margen bastante holgado de autonomía para la selección de los entrevistados y el personaje se selecciona a iniciativa propia, independientemente de que se acepten sugerencias de otras secciones.

El personaje entrevistado también condiciona el recibimiento que recibe en la redacción, aunque en este momento de la entrevista también influye la rutina de cada medio. En elmundo.es, por ejemplo, los propios personajes asisten a los Encuentros con cierto mecanicismo. En El País Digital sostienen que depende mucho del personaje y su interés informativo.

Las entrevistas se estructuran, desde el punto de vista narrativo, siguiendo un esquema redaccional más o menos fijo: titular, imagen de acompañamiento e introducción, que constituyen la cabecera, y cuerpo o desarrollo y cierre o despedida. En El País Digital, el titular se compone de dos elementos: el nombre del entrevistado, en mayúsculas y una frase entrecomillada de sus declaraciones seleccionada por el periodista. Por ejemplo, "Raphael: «Como soy perseverante, mi gran noche llegará»" (elpais.com, 3 de septiembre de 2013). Tras la imagen ilustrativa del entrevistado, en una breve introducción se presenta al personaje en cuestión, en la que se menciona, al menos, su profesión y se describe brevemente el género en el que se adentra el lector, así como una pincelada al motivo de actualidad del personaje. En la mencionada entrevista a Raphael, se optó por la siguiente introducción: "El músico charlará con los lectores de su carrera musical y de su gira por España 'Mi gran noche', que le está llevando por más de 30 ciudades de toda la geografía española". La cabecera se re- 
produce en la página de inicio de la sección de entrevistas, en la que una parte del título, las declaraciones del entrevistado, funcionan como enlace y la introducción se presenta resumida, actuando igualmente como gancho o teaser. En el interior, en la página de desarrollo, se pierde la parte del titular de la entrevista constituida por las declaraciones del entrevistado, y se añade la profesión del personaje.

Elmundo.es, por su parte, apuesta por una cabecera mucho más sencilla, compuesta por el nombre del entrevistado y la presentación, en la que se subraya la actualidad más reciente del personaje. Así presentaba, por ejemplo, este diario al compositor Luis Eduardo Aute, en la entrevista publicada el 22 de julio de 2013: “El niño que miraba el mar' es un trabajo que cuenta con doce nuevas canciones escritas y compuestas por él, y una película corta, 'El niño y el basilisco', con dibujos de animación, guión, dirección y música del autor. Dentro de los Veranos de la Villa, la noche del martes 30 en el Circo Price se proyectará la película y Luis Eduardo Aute presentará las canciones del disco, junto a otros temas conocidos por el público". En la página de inicio de sección se rescata el titular de la entrevista, que funciona como enlace, y una brevísima presentación del entrevistado. La de Aute, por ejemplo, quedaba así: "Presenta 'El niño que miraba el mar'”. En la página de desarrollo, tras la introducción, se salta directamente al cuerpo de la entrevista, constituido por el diálogo mantenido con los internautas siguiendo el clásico esquema compositivo de la entrevista de declaraciones, basado en la fórmula pregunta-respuesta, diferenciadas tipográficamente, que se van reproduciendo por orden de llegada.

El número de preguntas y respuestas es variable en ambos medios; depende, por ejemplo, de la extensión de las respuestas o del tiempo que se tome el entrevistado en responder a cada una de ellas. De esta forma, encontramos entrevistas con 25 preguntas y otras con 40. En cualquier caso, el número se ajusta a lo que posibilite el desarrollo de la entrevista, que se suele extender a lo largo de una hora. Por otro lado, El País Digital añade una breve llamada a la derecha, junto a cada pregunta, para indicar el nombre de usuario del entrevistado, el número de orden de la pregunta en el conjunto de la entrevista y la fecha y hora de publicación del ítem, con indicación exacta del minuto. Elmundo.es, por su parte, no aporta indicativos de tiempo.

El periodista desempeña en esta parte de la entrevista una importante función de filtro, pues gestiona el ritmo de la entrevista y modera las preguntas, seleccionando las más interesantes en función de criterios sumamente periodísticos, como la actualidad o la relevancia informativa. Además, en ambos medios se prescinde de las preguntas amenazantes o con insultos. Finalmente, los periodistas tienen que actuar ante la sobreabundancia de preguntas. En El País aseguran que en algunas entrevistas se han llegado a recibir hasta 3.000 preguntas, de las cuales han tenido que seleccionar unas 30 , aunque todo depende del interés informativo del personaje entrevistado. El redactor, además, auxilia al entrevistado en otras tareas, como la redacción de las respuestas. El nivel de intervención del periodista en esta faceta depende fundamentalmente del entrevistado. Hay personajes que, por su lentitud al teclado, necesitan de una ayuda integral del periodista, de manera que es el periodista quien redacta las respuestas a partir del dictado del entrevistado, independientemente de que después se ilustre la entrevista con una fotografía del personaje en cuestión frente al ordenador sujetando el 
ratón. Otros personajes necesitan simplemente una ayuda parcial. En El País, por ejemplo, corrigen las erratas propias de la escritura rápida frente a un teclado y algunas faltas de ortografía, mientras que en El Mundo se prefiere la literalidad del discurso, que aporta naturalidad y espontaneidad.

Pese a la intervención del periodista, el lenguaje resultante suele ser coloquial, con los matices propios del lenguaje oral. Se recurre con frecuencia, a marcadores discursivos, expresiones que no tienen ninguna función sintáctica en el marco de la predicación oracional. "Son muuuuy diferentes", contestaba Cristina Pardo en El Mundo (6 de agosto de 2013) a la pregunta de si le gustaba más el plató o el periodismo de calle. Además, respondió con un coloquial "Jajaja! No" cuando le preguntaron si cuando era joven se veía trabajando en la tele.

Las entrevistas se cierran con un mensaje de despedida, que visualmente aparece diferenciado del resto de los contenidos: en El País, recuadrado, con indicación de cierre (mensaje de despedida y con un color de fondo; en El Mundo, con indicación de cierre (despedida). El mensaje de despedida está constituido por un breve espacio de texto que se le concede al entrevistado para que escriba unas últimas palabras de adiós a los internautas. El entrevistado normalmente felicita a los lectores por haber pasado un rato agradable y al periódico por haberle dado la oportunidad de mantener el encuentro con los lectores, aunque algunos entrevistados aprovechan la ocasión para hacer promoción, como José María Îñigo, en el encuentro que mantuvo con los lectores de El Mundo el 26 de julio de 2013: "Que no me entere yo que no compráis el libro de 'Chupa la gamba' este verano porque así tendréis risa asegurada durante horas. Y, si os gusta la televisión, imprescindible leer 'La tele que fuimos'. Gracias a todos por las preguntas y espero volver a contestar nuevas preguntas dentro de 10 ó 15 años, cuando queráis. Y tomad nota de mi Twitter: @josemariainigo".

Por el tipo de preguntas que se realizan, Ainara Larrondo Ureta (2008:239) las asemeja a las entrevistas de personalidad, "centradas en la persona, no en sus declaraciones" (Larrondo Ureta, 2008:239), aunque la estructura se ciñe al esquema compositivo pregunta-respuesta, propio de la entrevista de declaraciones y también de la entrevista-perfil. El medio, además, intenta que las entrevistas se centren en un tema de actualidad relativo al entrevistado, al destacar, en la presentación, cuáles son los aspectos de mayor actualidad del personaje, pero la intervención de los lectores siempre cuenta con unos márgenes de libertad que expanden estos parámetros y extienden las preguntas hacia aspectos de la personalidad del entrevistado.

En cuanto a las imágenes que ilustran las entrevistas y, por tanto, la página contenedor, se prefieren claramente las imágenes que muestran al entrevistado posando junto al logotipo de los medios, de manera que la imagen de marca puede visualizarse en la fotografía total o parcialmente. Estas tomas evidencian la presencia física del entrevistado en la sala de redacción del periódico. El País apuesta claramente por este tipo de imágenes. Otras veces el entrevistado es fotografiado sin logo, sentado junto a un ordenador, en una sala que rápidamente permite ser identificada como la redacción o un despacho del periódico. Ambas modalidades de fotografía confieren credibilidad y cercanía a la entrevista. En algunas ocasiones, aunque escasas, este periódico opta por fotografías de grupo, en las que el entrevistado aparece rodeado de visitas. 
En un menor número de ocasiones las entrevistas se ilustran con un retrato del entrevistado, de archivo o realizada al efecto, que no permite advertir su presencia en la sala de redacción y que, por tanto, connotan mayor distancia. El Mundo, por su parte, se decanta por un tipo casi único de imágenes en las que se puede ver al entrevistado sentado, de medio cuerpo, mirando a cámara, con un logotipo de fondo creado expresamente para la sección de Encuentros del diario. De esta forma, los distintos entrevistados desfilan por las imágenes en posiciones afines, con un mismo fondo, como si se tratara de un photocall.

El País Digital concede una importancia destacada a la imagen, que también pueden consultarse Facebook. En elmundo.es la complementariedad con las redes sociales también queda patente. De hecho, en la sección de encuentros digitales dispone de un enlace a la página de Facebook en la que pueden seguirse las entrevistas, comentar o compartir los encuentros.

\section{Conclusiones}

La participación del lector es, sin duda, una de las grandes apuestas de los medios digitales. Favorecida por las propiedades intrínsecas de la red en materia de interactividad, las innovaciones ya han dejado su impronta en el panorama actual de los géneros periodísticos, especialmente en el bloque de géneros dialógicos, en los que se tiende a fomentar la participación del usuario, como los foros, los canales de charla (chats) o las entrevistas de los lectores. En cualquier caso, asistimos al inicio de un largo camino en lo que a las posibilidades para la participación ciudadana se refiere.

En el caso de las entrevistas de los lectores, un género dialógico e interactivo en el que los usuarios tienen la posibilidad de entrevistar a un personaje de actualidad propuesto por el medio, los dos grandes medios de referencia en España, como El Pais Digital y elmundo.es, tienden a reforzar su presencia en el periódico con una sección propia, denominada "Entrevistas" y "Encuentros", respectivamente, en la que también se anuncian próximas citas, se almacenan álbumes de fotos, se insertan vínculos que fomentan la complementariedad de contenidos y sinergia con las redes sociales. Además, en esta página se dispone de material hemerográfico y sistemas de búsqueda para localizar entrevistas pasadas que no disponen de vínculos directos en la página principal de la sección. Con esta ubicación en una página contenedor íntegramente dedicada al género, se cumple un doble objetivo: por un lado, las entrevistas de los lectores aparecen diferenciadas de otros textos de producción eminentemente periodística; por otro lado, se unifican contenidos de participación ciudadana y se les confiere cierta relevancia. Finalmente, la inserción de la cabecera de la entrevista en la página de inicio del medio fomenta la integración natural de contenidos de participación ciudadana entre los contenidos absolutamente periodísticos del medio.

Aunque las entrevistas de los lectores se pueden desarrollar en directo o en diferido, los medios apuestan claramente por el directo, que aporta vivacidad al relato. También se prefiere la presencia del entrevistado en la sala de redacción del medio, que fortalece la imagen de marca y fideliza audiencias.

La participación de los lectores confiere al género un estilo natural, con un lenguaje en el que predominan códigos lingüísticos propios del lenguaje oral. Pese a ello, 
es un género sumamente planificado, en el que el periodista desempeña un importante papel en las distintas fases de la entrevista: previamente, en la selección de los entrevistados y la planificación de los encuentros con material documental; durante la entrevista, gestionando su ritmo, moderando las preguntas y seleccionando las cuestiones de mayor interés informativo. Además, el periodista puede auxiliar al entrevistado en la redacción de las respuestas. Finalmente, al periodista también le aguardan algunas funciones a posteriori, pues en algunos medios revisan las respuestas, corrigen erratas y faltas de ortografía y seleccionan la respuesta más destacada, que formará parte del titular. De esta forma, el desarrollo de los géneros para la participación dialógica del internauta y, en concreto, las entrevistas de los lectores, también conlleva nuevas exigencias profesionales para los periodistas, en un contexto en el que asistimos a una profunda transformación de las rutinas y tareas periodísticas.

La participación del lector es, en todo caso, limitada y está circunscrita a las normas del medio y las pautas que va marcando el periodista que, de esta forma, asume en el tiempo, más allá del rol de moderador, una función educativa de la audiencia y de instrucción en cuanto a las posibilidades para la participación. El periodista vela por el cumplimiento de unos principios éticos y, desde el punto de vista compositivo, intenta imprimir a las aportaciones de los usuarios en la entrevista de los lectores la lógica de los textos periodísticos profesionales. De ahí que Deuze (2003: 205) observe que los medios tienden a expandir sus posibilidades en Internet basándose en la cultura periodística preexistente, equivalente a un periodismo profesional.

Hoy por hoy, las entrevistas de los lectores constituyen un género periodístico con una amplia presencia en los medios, aunque por el momento no gozan de una periodicidad y un horario fijos, indicadores de la consolidación de un género. Le aguardan, además, algunos retos, como potenciar los sistemas de seguimiento en las redes sociales, fomentar su visibilidad en el conjunto de los contenidos del medio y reforzar el papel del periodista en tareas de edición, de manera que se dote al género de algunos rasgos propios que lo definan con más claridad en el entorno del diario digital, un reto que se abre paso cada día reforzando su presencia y su identidad como un género periodístico autónomo en el que los lectores también tienen la palabra.

\section{Referencias bibliográficas}

ÁLVAREZ MARCOS, José (2000): Sevilla y el Periodismo multimedia: la experiencia pionera de Diario Expo 92. Sevilla, Padilla Libros.

CABRERA GONZÁLEZ, Ma Ángeles (2001): “Convivencia de la prensa escrita y la prensa on-line en su transición hacia el modelo de comunicación multimedia". Estudios sobre el mensaje periodístico, vol. 7. pp. 71-78. Madrid, Servicio de Publicaciones de la Universidad Complutense.

CEBRIÁN HERREROS, Mariano (1995): Información audiovisual. Concepto, técnica, expresión y aplicaciones. Madrid, Síntesis.

CEBRIÁN HERREROS, Mariano (2009): “Comunicación interactiva en los cibermedios”. Revista Comunicar, 33, pp. 15-24. (DOI:10.3916/c33-2009-02-001) 
DEUZE, Mark (2003): "The Web and Its Journalisms: considering the consequences of different types of news media online". New Media \& Society 5(2), pp. 203-230 (DOI: $10.1177 / 1461444803005002004)$

DÍAZ NOCI, Javier (2001): La escritura digital. Hipertexto y construcción del discurso informativo en el periodismo electrónico. Guipuzkoa, Universidad del País Vasco.

DÍAZ NOCI, Javier (2004): Los géneros cibernéticos: una aproximación teórica a los cibertextos, sus elementos y tipología. Ponencia presentada al II Congreso Iberoamericano de Periodismo digital. Santiago de Compostela, 29-30 de noviembre, (www.ehu.es/diaz-noci/Conf/santiago04.pdfg) (16-01-2008).

EDO, Concha (2009): Periodismo informativo e interpretativo. El impacto de Internet en la noticia, las fuentes y los géneros. Sevilla, Comunicación Social Ediciones y Publicaciones.

ELOLA, Joseba (2010): "Yo no dejaría el destino de las noticias en manos de Google" [en línea], entrevista a Bill Keller, director de 'The New York Times', El País Digital, 25 de julio, (www.elpais.com/diario/2010/07/25/domingo/1280029954 _850215.html) (08-09-2013)

HERMIDA, Alfred y THURMAN, NEil (2008): “A clash of cultures. The integration of user-generated content within professional journalistic frameworks at British newspaper websites". Journalism Practice, 2:3, pp. 343-356 (DOI: 10.1080/17512780802054538).

HERRERA DAMAS, Susana (2003): “Tipología de la participación de los oyentes en los programas de radio". Anàlisi: Quaderns de comunicació $i$ cultura, no 30, pp. 145-166.

LARRONDO, Ainara (2008): Los géneros en la Redacción Ciberperiodística. Contexto, teoría y práctica actual. Leioa, Servicio Editorial de la Universidad del País Vasco.

LÓPEZ HIDALGO, Antonio (2005): "Los géneros periodísticos en la red: una clasificación posible para un medio en evolución". Estudios de Periodismo, n ${ }^{\circ}$ 9, pp. 14. http://www.periodismoudec.cl/estudiosdeperiodismo/index.php?option=com content\&task $=$ view\&id $=45 \&$ Itemid $=53$

LÓPEZ HIDALGO, Antonio (1999): Las Entrevistas Periodísticas de José María Carretero. Córdoba, Diputación de Córdoba.

LÓPEZ HIDALGO, Antonio y FERNÁNDEZ BARRERO, Ma Ángeles (2008): "Nuevos retos para el periodista profesional en pleno auge del periodismo participativo". Comunicación presentada en el V Colóquio Brasil-Espanha de Ciências da Comunicação, Políticas de Comunicação e da Cultura: contribuições acadêmicas e intervenção social. Brasília: Sociedade Brasileira de Estudios Interdisciplinares da Comunicação, pp. 1-11.

MANCERA, Ana (2011): ¿Cómo se "habla” en los cibermedios? El español coloquial en el periodismo digital. Berna: Peter Lang AG. 
MAYORAL, Javier (2013): Redacción Periodística. Medios, géneros y formatos. Madrid, Editorial Síntesis.

NEGREDO BRUNA, Samuel (2013): "Participation in Al Jazeera English: integrating witnesses and users to roaden the reach of the news". Communication\&Society/Comunicación y Sociedad, Vol. 26, n 1, pp. 1-21.

SALAVERRÍA, Ramos (coord., 2005): Cibermedios. El impacto de Internet en los medios de comunicación en España. Sevilla, Comunicación Social Ediciones y Publicaciones.

SALAVERRÍA, Ramos (2007): "Ciberperiodismo: diez años de prensa digital en España”, en FERNÁNDEZ SANZ, Juan José (ed.): Doce calas. Prensa especializada. Madrid, MCGraw-Hill/Interamericana de España, S.A.U.

VEGLIS, Andreas y POMPORTSIS, Andreas (2012): "The e-citizen in the cyberspace - a journalism aspect". 25th International Conference on Information Law and Ethics. https://auth.academia.edu/AndreasVeglis [Consulta: 10/09/2013] 